\title{
Implications of the VerifyNow P2Y12 Assay on Patient Outcomes
}

\author{
Denise A. Sutter, Gregory S. King, Marintha R. Short \\ Department of Pharmacy Services, Saint Joseph Hospital, Lexington, USA \\ Email: denisesutter1@gmail.com
}

Received 24 June 2014; revised 24 July 2014; accepted 24 August 2014

Copyright (C) 2014 by authors and Scientific Research Publishing Inc.

This work is licensed under the Creative Commons Attribution International License (CC BY). http://creativecommons.org/licenses/by/4.0/

(c) (i) Open Access

\section{Abstract}

Background: The platelet inhibitory response of clopidogrel is substantially variable among patients, and numerous studies have shown that post-percutaneous intervention, patients with high on-treatment platelet reactivity have an increase in risk of major adverse cardiovascular events. No published studies to date have utilized platelet function monitoring assays prior to coronary artery bypass graft (CABG) surgery, but determination of patients' antiplatelet effects prior to surgery may decrease time to surgery and length of hospital stay. The purpose of the study was to evaluate the clinical outcomes of non-elective CABG patients analyzed by the VerifyNow P2Y12 platelet-function monitoring assay prior to surgery compared to a similar set of patients not analyzed by the VerifyNow P2Y12 assay. Methods: This was a retrospective, single center, cohort study. The primary endpoints of this study were time to surgery and length of hospital stay. Results: From March 2013 to July 2013, 60 patient charts were reviewed and included in this study. 49 patients were analyzed by the VerfiyNow P2Y12 assay, and 16 of these patients underwent non-elective CABG surgery. Eleven patients underwent non-elective CABG surgery and were not analyzed by the VerifyNow P2Y12 assay. There was no difference between groups regarding time to surgery $(p=0.75)$ or length of stay $(p=0.42)$. Based on the assay's P2Y12 reaction unit results, $69 \%$ of VerifyNow P2Y12 patients went to surgery sooner than the institution's recommendations which generated more bleeding events, half of which were considered major bleeds. Conclusions: Utilization of the VerifyNow P2Y12 assay prior to non-elective CABG surgery does not shorten time to surgery or overall length of hospital stay. However, insufficient P2Y12 reaction units prior to surgery may lead to more bleeding events, thus the application of platelet function monitoring assays prior to procedures may be beneficial as a bleeding risk-assessment tool.

\section{Keywords}

Coronary Artery Bypass Graft Surgery, CABG, Clopidogrel, VerifyNow P2Y12, Platelet Function Monitoring Assay 


\section{Introduction}

Dual anti-platelet therapy is part of the standard of care provided to acute coronary syndrome (ACS) patients. The current ACCF/AHA/SCAI guidelines for percutaneous coronary intervention (PCI) recommend ACS patients undergoing PCI with stenting be administered a loading dose of a P2Y12 receptor inhibitor (either clopidogrel, prasugrel, or ticagrelor) followed by a lower, maintenance dose for at least twelve months [1]. In contrast, the ACCF/AHA guidelines for coronary artery bypass graft (CABG) surgery recommend patients referred for elective CABG discontinue clopidogrel and ticagrelor for at least 5 days prior to surgery and prasugrel for at least 7 days to limit bleeding complications. Patients referred for urgent CABG should discontinue clopidogrel and ticagrelor for at least 24 hours to reduce major bleeding complications [2]. Although the guidelines differ in the amount of antiplatelet activity needed, both emphasize the importance of maintaining hemostatic balance.

The platelet inhibitory response of clopidogrel is substantially variable among patients [3]-[6]. Additionally, numerous studies have shown that high on-treatment platelet reactivity with clopidogrel is associated with an increased risk of cardiovascular events (e.g. cardiovascular death, nonfatal myocardial infarction, stent thrombosis) after PCI [7]-[11]. Through these findings, platelet function monitoring assays have been developed to provide better risk stratification of patients and to help guide clinical decisions. Light transmittance aggregometry (LTA) with adenosine diphosphate (ADP) stimulation is the current gold standard assay; however, it is not suitable for routine clinical practice. LTA has proven to be time-consuming, requires intensive sample preparation by an experienced technician, and the results are not instantaneous [12] [13]. In lieu of these disadvantages, alternative platelet function assays have been developed to provide point-of-care testing. One such assay, VerifyNow P2Y12, has been developed and approved by the Food and Drug Administration (FDA) to specifically and rapidly monitor the inhibitory effects of thienopyridine-therapy. VerifyNow P2Y12 compares the platelet reactivity of the blood sample to the sample's baseline platelet function and reports results as BASE (an estimate of the patient's baseline platelet function independent of P2Y12 receptor inhibition), P2Y12 reaction units (PRU), and percent platelet inhibition [13] [14]. Several head-to-head comparisons between the VerifyNow P2Y12 assay and LTA have been completed with the majority of trials revealing significant correlation between the two methods of measurement [15]-[18].

The current literature utilizes these antiplatelet assays post-PCI to determine potential drug efficacy by measuring the platelet inhibitor response in patients. According to the manufacturer, a PRU value less than or equal to 208 represents specific evidence for the presence of expected antiplatelet effect and is associated with reduced rates of thrombosis. Additionally, lower PRU values are associated with risk for bleeding, and measurements less than 95 are considered to be at highest risk for major bleeding [14]. When evaluating patients with high on-treatment platelet reactivity post-PCI, several studies have used PRU cutoffs of 230 or greater based on receiver-operating characteristic (ROC) curve analyses [19]-[23]. ROC curve analyses identify the level of ontreatment reactivity that provided the maximal sensitivity and specificity for the prediction of major adverse cardiovascular events after PCI [23]. Based on these interpretations, if these point-of-care assays were to be used prior to surgery, patients not exhibiting the desired antiplatelet effect would have higher than expected platelet aggregation and may be able to go to surgery sooner without increasing their risk for bleeding. With these presumptions, our institution implemented the utilization of the VerifyNow P2Y12 assay in 2009 as part of the cardiothoracic vascular surgery pre-operation protocol. The purpose of this retrospective study is to evaluate the clinical outcomes of non-elective CABG patients analyzed by the VerifyNow P2Y12 assay compared to similar patients who were not analyzed by the assay.

\section{Methods}

This study was designed as a retrospective, single-center, cohort study. The trial was conducted at a 433-bed tertiary care center that serves as a primary cardiac hospital in its community. Patients were included if they underwent non-elective CABG surgery between March 2013 and July 2013. Patients were excluded if they were less than 18 years old, were not on a P2Y12 inhibitor at home, or did not receive a dose of a P2Y12 inhibitor prior to surgery.

Eligible patients were separated into two groups: those who were analyzed by the VerifyNow P2Y12 assay and those who were not. A subpopulation of any patient who received the VerifyNow P2Y12 assay during the study period was also obtained in order to determine other clinical settings in which the assay was being utilized. The results of the VerifyNow P2Y12 assay were interpreted using the manufacturer and institution's recom- 
mendations. Post-procedure, a PRU $<208$ was representative of the expected antiplatelet effect. Pre-procedure, a PRU $>250$ was indicative of sufficient platelet aggregation to proceed with surgery.

The primary endpoints were time to surgery and length of hospital stay. Secondary endpoints included the clinical utility of the VerifyNow P2Y12 assay, changes in antiplatelet therapy post-surgery, composite and individual instance of all-cause death, myocardial infarction, stent thrombosis, stroke, and target vessel revascularization, and the rates of major and minor bleeding. Time to surgery was defined as time from admission to time of CABG surgery in hours. Length of hospital stay was defined as time from admission to hospital discharge. Bleeding events were defined by the thrombolysis in myocardial infarction (TIMI) bleeding criteria. Major bleeds included intracranial hemorrhage or a $5 \mathrm{gm} / \mathrm{dL}$ decrease in hemoglobin concentration or a $15 \%$ absolute decrease in the hematocrit. If CABG related, major bleeds included fatal bleeding, perioperative intracranial bleeding, transfusion of at least 5 units of whole blood, reoperation following closer of sternotomy incision for the purpose of controlling bleeding, receiving packed red blood cells within a $48 \mathrm{~h}$ period, and chest tube output $>2$ $\mathrm{L}$ within a $24 \mathrm{~h}$ period. Minor bleeds were defined as any clinically overt sign of hemorrhage that is associated with a fall in hemoglobin of 3 to $5 \mathrm{gm} / \mathrm{dL}$ or a fall in hematocrit $9 \%$ to $\leq 15 \%$.

\section{Statistical Analysis}

Data was analyzed using Microsoft Excel. Continuous data were analyzed using a log10-transformed student t-test to decrease the variance among data. Categorical data were analyzed using a Chi-square test or a Fischer's exact test if the sample size of any subgroup was less than or equal to five. All tests used a 95\% confidence interval with an alpha less than or equal to 0.05 .

\section{Results}

From March 2013 through July 2013, 60 patients were reviewed and included in the study. Forty-nine patients were analyzed by the VerifyNow P2Y12 assay. Sixteen of these 49 patients of these patients underwent nonelective CABG surgery and the remaining 33 patients underwent elective CABG surgery or other procedures. Eleven of the 60 patients underwent non-elective CABG surgery and were not analyzed by the VerifyNow P2Y12 assay and served as the control group (Figure 1).

Among all 49 patients analyzed by the assay, 25 (51\%) underwent CABG surgery with 16 (32.7\%) being nonelective and 9 (18.4\%) being elective. Other utilizations of the assay included 3 bronchoscopies (6.1\%), 4 thoracotomies/thoracoscopies (8.2\%), 3 endarterectomies (6.1\%), 6 vascular procedures (12.2\%), 6 left heart catheterizations/angiograms/PCI (12.2\%), 3 heart valve repair/replacements (6.1\%), and 5 other procedures (10.2\%) (Table 1). Further interpretation of PRU values were only conducted for non-elective CABG patients.

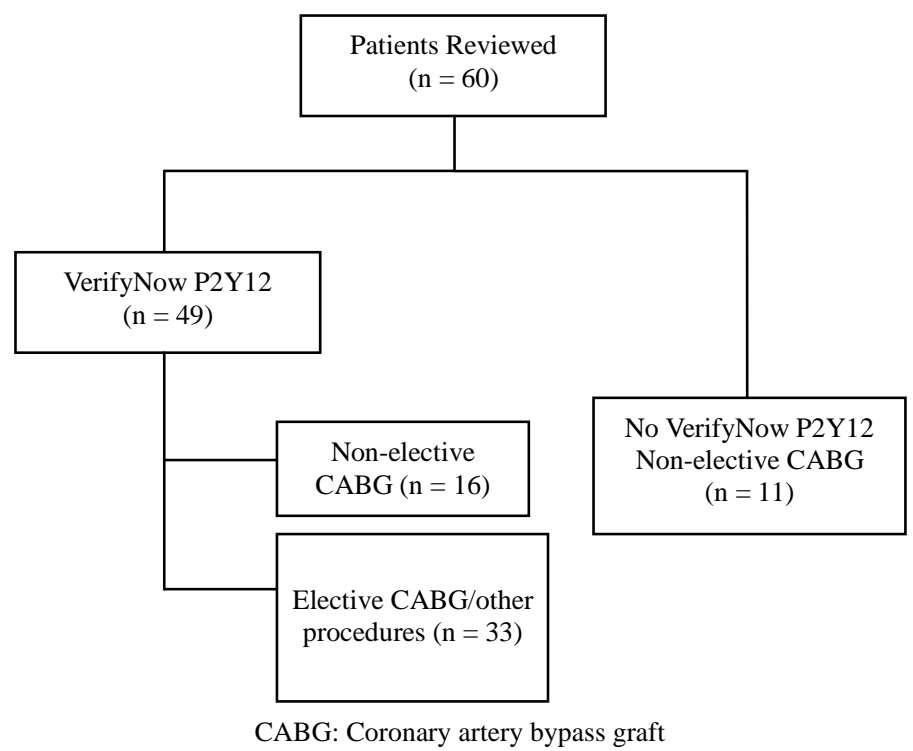

Figure 1. Patient population. 
Table 1. VerifyNow P2Y12 patient subpopulation.

\begin{tabular}{lc}
\hline \multicolumn{1}{c}{ Procedure } & $\begin{array}{c}\text { VerifyNow P2Y12 } \\
\text { Patients n }=49(\%)\end{array}$ \\
\hline CABG & \\
• Non-elective CABG & $16(32.7 \%)$ \\
• Elective CABG & $9(18.4 \%)$ \\
Bronchoscopy & $3(6.1 \%)$ \\
Thoracotomy/Thoracoscopy & $4(8.2 \%)$ \\
Endarterectomy & $3(6.1 \%)$ \\
Vascular procedure & $6(12.2 \%)$ \\
Left heart catheterization/angiogram/PCI & $6(12.2 \%)$ \\
Heart valve repair/replacement & $3(6.1 \%)$ \\
Other & $5(10.2 \%)$ \\
\hline
\end{tabular}

Baseline characteristics of non-elective CABG patients were similar among both study groups, with the only significant difference being more diabetic patients in the VerifyNow P2Y12 group. On average, patients were 60 years old with $50 \%-60 \%$ of the study population being male. More than $90 \%$ of patients were Caucasian with normal renal function. The average hemoglobin and hematocrit were $12 \mathrm{~g} / \mathrm{dL}$ and $38 \%$ respectively, and the majority of patients also had coronary artery disease, hypertension, and dyslipidemia as comorbidities (Table 2).

Overall, there were no significant differences among the primary endpoints of this study. Time to surgery was very similar between the two groups with the mean time being $69.4 \mathrm{hr}$ in the VerifyNow P2Y12 group and 79.4 $\mathrm{h}$ in the control group $(\mathrm{p}=0.75)$. Patients who were analyzed by the VerifyNow P2Y12 assay had a shorter length of stay, 9.8 days, compared to the control group, 12.4 days, but this finding was not statistically significant $(\mathrm{p}=0.42)($ Table 3$)$.

With regards to secondary endpoints, fewer percentage of patients who were analyzed by the VerifyNow P2Y12 assay had changes in antiplatelet therapy post-CABG surgery (10 out of 16 (62.5\%) VerifyNow P2Y12 patients vs. 9 out of 11 (81.8\%) control patients); however, this finding was not statistically significant ( $\mathrm{p}=0.2)$. In both groups, the most common change in antiplatelet therapy was not restarting the P2Y12 inhibitor postCABG surgery. There were no incidences of death, myocardial infarction, stent thrombosis, stroke, and/or target vessel revascularization among the VerifyNow P2Y12 patients, and 1 case of stroke and 1 case of death among the control patients.

Non-elective CABG patients analyzed by the VerifyNow P2Y12 assay had more bleeding events (including individual major and minor bleeds) than those not analyzed by VerifyNow; however, none of these events were statistically significant (Table 4). When analyzing the PRU values of the non-elective CABG VerifyNow P2Y12 patients, only 5 out of 16 patients (31.3\%) had a PRU > 250 per institution protocol. Twelve out of 16 patients (75\%) had a bleeding event, and half of these were major bleeds. Of these major bleeds, all except one had a PRU $<250$. Seven out of 16 patients received blood products (43.8\%), and all had PRU values < 250 (Table 5).

\section{Discussion}

The current utility of platelet function monitoring assays is post-PCI to identify patients with high-on treatment platelet reactivity that are at an increased risk of major adverse cardiovascular events. Although no studies have used these assays prior to CABG surgery, determination of antiplatelet effects prior to surgery has the potential to decrease time to surgery for patients exhibiting decreased response to P2Y12 inhibitors. Additionally, if patients undergo CABG procedures sooner due to inadequate platelet inhibition, the overall length of hospital stay may be decreased without an increased risk of bleeding. This study did not find that the application of the VerifyNow P2Y12 assay impacted the time to surgery or length of hospital stay. This could have been due to the 
Table 2. Baseline characteristics.

\begin{tabular}{cccc}
\hline & $\begin{array}{c}\text { VerifyNow non-elective } \\
\text { CABG (n=16) }\end{array}$ & $\begin{array}{c}\text { No VerifyNow non-elective } \\
\text { CABG (n = 11) }\end{array}$ & p-value \\
\hline Age (yr) & $63.3(10.2)$ & $60.6(10.2)$ & 0.51 \\
Male & $8(50.0)$ & $7(63.6)$ & 0.48 \\
Caucasian & $15(93.8)$ & $11(100)$ & 0.40 \\
Height (cm) & $167.5(9.3)$ & $170.1(14.6)$ & 0.59 \\
Weight (kg) & $84.9(14.5)$ & $96.8(19.4)$ & 0.72 \\
Serum Creatinine (mg/dL) & $1.1(0.9)$ & $1.2(0.5)$ & 0.94 \\
Hemoglobin (g/dL) & $12.7(1.6)$ & $12.6(2.5)$ & 0.69 \\
Hematocrit (\%) & $38.6(3.5)$ & $37.7(6.7)$ & 0.30 \\
Platelet Count (K/uL) & $250.6(73.2)$ & $216.7(93.3)$ & 0.50 \\
Co-Morbid Disease States & & & 0.68 \\
Hypertension & $15(93.8)$ & $10(90.9)$ & 0.04 \\
Dyslipidemia & $13(81.3)$ & $9(81.8)$ & 0.59 \\
Diabetes & $11(68.8)$ & $3(27.3)$ & 0.34 \\
Coronary Artery Disease & $15(93.8)$ & $11(100)$ & 0.64 \\
\hline Peripheral Vascular Disease & $2(12.5)$ & $0(0.0)$ & $1(9.1)$ \\
\hline
\end{tabular}

Data are mean $( \pm \mathrm{SD})$ or number $(\%)$.

Table 3. Primary endpoints.

\begin{tabular}{ccc}
\hline & VerifyNow P2Y12 $(\mathrm{n}=16)$ & No VerifyNow P2Y12 $(\mathrm{n}=11)$ \\
\hline Time to Surgery (hours) & $69.4 \pm 60.5$ & $79.4 \pm 115.9$ \\
Length of Hospital Stay (days) & $9.8 \pm 4.0$ & $12.4 \pm 10.1$ \\
\hline
\end{tabular}

Data are mean $( \pm S D)$.

Table 4. Bleeding events.

\begin{tabular}{|c|c|c|c|}
\hline & VerifyNow P2Y12 (n = 16) & No VerifyNow P2Y12 (n=11) & p-value \\
\hline Any Bleeding Event & $12(75 \%)$ & $7(63.6 \%)$ & 0.53 \\
\hline Major Bleeding Event & $6(37.5 \%)$ & $4(36.4 \%)$ & 0.95 \\
\hline Minor Bleeding Event & 7 (43.8\%) & $3(27.3 \%)$ & 0.38 \\
\hline
\end{tabular}

Data are number (\%).

small sample size of both groups which restricts the ability to determine significant difference. In addition, starting the time to surgery from admission could have skewed the overall results because chart reviews revealed that numerous patients were originally admitted for non-cardiac reasons, and a subsequent heart catheterization performed later during the admission determined the need for urgent CABG surgery. It would have been more accurate to define time to surgery as time from heart catheterization to initiation of CABG surgery, but this data was not available for all patients included in this study.

The most common change in antiplatelet therapy post-CABG was discontinuation of the P2Y12 inhibitor. Since the current 2011 ACC/AHA practice guidelines for CABG do not recommend dual-antiplatelet therapy 
Table 5. PRU values, bleeding events, and use of blood products.

\begin{tabular}{ccc}
\hline PRU & Bleeding Event $(\mathrm{Y} / \mathrm{N})$ & Use of Blood Products $(\mathrm{Y} / \mathrm{N})$ \\
\hline 195 & Yes & Yes \\
198 & Yes & No \\
248 & Yes-major bleed & Yes \\
124 & Yes-major bleed & Yes \\
225 & Yes & No \\
206 & No & No \\
142 & Yes & No \\
$274^{*}$ & Yes-major bleed & No \\
170 & Yes-major bleed & Yes \\
243 & Yes-major bleed & Yes \\
288 & No & No \\
194 & Yes-major bleed & Yes \\
205 & Yes & Yes \\
269 & No & No \\
317 & No & No \\
254 & Yes & No \\
\hline
\end{tabular}

*Pt had VerifyNow P2Y12 assay performed three times prior to surgery to achieve a PRU > 250; PRU = P2Y12 Reaction Units.

post-CABG, continuing aspirin only was in accordance with current practice [2]. This study did show that lower PRU values lead to more bleeding events despite no statistical significance. In addition, there were significantly more diabetic patients among those who received the VerifyNow P2Y12 assay; however, it is unlikely that this difference majorly impacted the overall results. Diabetes is not an independent risk factor for bleeding in hospitalized patients according to the 2012 Antithrombotic Therapy and Prevention of Thrombosis CHEST guidelines, and a significant difference may not be apparent in a larger patient population [24].

Although no clinical trials have assessed PRU values prior to surgery, the results of this study suggest that PRU values $<250$ provide insufficient platelet aggregation and bleeding risks versus benefits should be evaluated prior to surgery. Despite the overall lack of statistical significance, this study shows the potential utilization of platelet-function monitoring assays prior to CABG surgery to help assess benefits versus risk of bleeding.

\section{Conclusion}

Utilization of the VerifyNow P2Y12 assay prior to non-elective CABG surgery does not shorten time to surgery or overall length of hospital stay. Despite these findings, application of platelet function monitoring assays prior to procedures may be beneficial at assessing patients' risk of bleeding since lower P2Y12 reaction units prior to surgery may lead to more bleeding events.

\section{References}

[1] Levine, G.N., Bates, E.R., Blankenship, J.C., Bailey, S.R., Bittl, J.A., Cercek, B., Chambers, C.E., Ellis, S.G., Guyton, R.A., Hollenberg, S.M., Khot, U.N., Lange, R.A., Mauri, L., Mehran, R., Moussa, I.D., Mukherjee, D., Nallamothu, B.K. and Ting, H.H. (2011) 2011 ACCF/AHA/SCAI Guideline for Percutaneous Coronary Intervention: A Report of the American College of Cardiology Foundation/American Heart Association Task Force on Practice Guidelines and the Society for Cardiovascular Angiography and Interventions. Circulation, 124, e574-e651.

http://dx.doi.org/10.1161/CIR.0b013e31823ba622 
[2] Hillis, L.D., Smith, P.K., Anderson, J.L., Bittl, J.A., Bridges, C.R., Byrne, J.G., Cigarroa, J.E., Disesa, V.J., Hiratzka, L.F., Hutter Jr., A.M., Jessen, M.E., Keeley, E.C., Lahey, S.J., Lange, R.A., London, M.J., Mack, M.J., Patel, M.R., Puskas, J.D., Sabik, J.F., Selnes, O., Shahian, D.M., Trost, J.C. and Winniford, M.D. (2011) 2011 ACCF/AHA Guideline for Coronary Artery Bypass Graft Surgery: A Report of the American College of Cardiology Foundation/American Heart Association Task Force on Practice Guidelines. Circulation, 124, e652-e735. http://dx.doi.org/10.1161/CIR.0b013e31823c074e

[3] Angiolillo, D.J., Fernandez-Ortiz, A., Bernardo, E., Alfonso, F., Macaya, C., Bass, T.A. and Costa, M.A. (2007) Variability in Individual Responsiveness to Clopidogrel: Clinical Implications, Management, and Future Perspectives. Journal of the American College of Cardiology, 49, 1505-1516. http://dx.doi.org/10.1016/j.jacc.2006.11.044

[4] Gurbel, P.A., Bliden, K.P., Hiatt, B.L. and O’Connor, C.M. (2003) Clopidogrel for Coronary Stenting: Response Variability, Drug Resistance, and the Effect of Pretreatment Platelet Reactivity. Circulation, 107, 2908-2913. http://dx.doi.org/10.1161/01.CIR.0000072771.11429.83

[5] Price, M.J., Coleman, J.L., Steinhubl, S.R., Wong, G.B., Cannon, C.P. and Teirstein, P.S. (2006) Onset and Offset of Platelet Inhibition after High-Dose Clopidogrel Loading and Standard Daily Therapy Measured by a Point-of-Care Assay in Healthy Volunteers. American Journal of Cardiology, 98, 681-684.

http://dx.doi.org/10.1016/j.amjcard.2006.03.054

[6] Serebruany, V.L., Steinhubl, S.R., Berger, P.B., Malinin, A.I., Bhatt, D.L. and Topol, E.J. (2005) Variability in Platelet Responsiveness to Clopidogrel among 544 Individuals. Journal of the American College of Cardiology, 45, $246-251$. http://dx.doi.org/10.1016/j.jacc.2004.09.067

[7] Geisler, T., Langer, H., Wydymus, M., Gohring, K., Zurn, C., Bigalke, B., Stellos, K., May, A.E. and Gawaz, M. (2006) Low Response to Clopidogrel Is Associated with Cardiovascular Outcome after Coronary Stent Implantation. European Heart Journal, 27, 2420-2425. http://dx.doi.org/10.1093/eurheartj/ehl275

[8] Marcucci, R., Gori, A.M., Paniccia, R., Giusti, B., Valente, S., Giglioli, C., Buonamici, P., Antoniucci, D., Abbate, R. and Gensini, G.F. (2009) Cardiovascular Death and Nonfatal Myocardial Infarction in Acute Coronary Syndrome Patients Receiving Coronary Stenting Are Predicted by Residual Platelet Reactivity to ADP Detected by a Point-of-Care Assay: A 12-Month Follow-Up. Circulation, 119, 237-242. http://dx.doi.org/10.1161/CIRCULATIONAHA.108.812636

[9] Price, M.J., Endemann, S., Gollapudi, R.R., Valencia, R., Stinis, C.T., Levisay, J.P., Ernst, A., Sawhney, N.S., Schatz, R.A. and Teirstein, P.S. (2008) Prognostic Significance of Post-Clopidogrel Platelet Reactivity Assessed by a Point-ofCare Assay on Thrombotic Events after Drug-Eluting Stent Implantation. European Heart Journal, 29, 992-1000. http://dx.doi.org/10.1093/eurheartj/ehn046

[10] Sibbing, D., Braun, S., Morath, T., Mehilli, J., Vogt, W., Schomig, A., Kastrati, A. and von Beckerath, N. (2009) Platelet Reactivity after Clopidogrel Treatment Assessed with Point-of-Care Analysis and Early Drug-Eluting Stent Thrombosis. Journal of the American College of Cardiology, 53, 849-856. http://dx.doi.org/10.1016/j.jacc.2008.11.030

[11] Yamaguchi, Y., Abe, T., Sato, Y., Matsubara, Y., Moriki, T. and Murata, M. (2013) Effects of VerifyNow P2Y12 Test and CYP2C19*2 Testing on Clinical Outcomes of Patients with Cardiovascular Disease: A Systematic Review and Meta-Analysis. Platelets, 24, 352-361. http://dx.doi.org/10.3109/09537104.2012.700969

[12] Sambu, N. and Curzen, N. (2011) Monitoring the Effectiveness of Antiplatelet Therapy: Opportunities and Limitations. British Journal of Clinical Pharmacology, 72, 683-696. http://dx.doi.org/10.1111/j.1365-2125.2011.03955.x

[13] van Werkum, J.W., Harmsze, A.M., Elsenberg, E.H., Bouman, H.J., ten Berg, J.M. and Hackeng, C.M. (2008) The Use of the VerifyNow System to Monitor Antiplatelet Therapy: A Review of the Current Evidence. Platelets, 19, 479-488. http://dx.doi.org/10.1080/09537100802317918

[14] VerifyNow P2Y12 Platelet Reactivity Test [Package Insert]. Accumetrics, San Diego, CA, 2013.

[15] Jakubowski, J.A., Payne, C.D., Li, Y.G., Brandt, J.T., Small, D.S., Farid, N.A., Salazar, D.E. and Winters, K.J. (2008) The Use of the VerifyNow P2Y12 Point-of-Care Device to Monitor Platelet Function across a Range of P2Y12 Inhibition Levels Following Prasugrel and Clopidogrel Administration. Thrombosis and Haemostasis, 99, 409-415.

[16] Paniccia, R., Antonucci, E., Gori, A.M., Marcucci, R., Giglioli, C., Antoniucci, D., Gensini, G.F., Abbate, R. and Prisco, D. (2007) Different Methodologies for Evaluating the Effect of Clopidogrel on Platelet Function in High-Risk Coronary Artery Disease Patients. Journal of Thrombosis and Haemostasis, 5, 1839-1847. http://dx.doi.org/10.1111/j.1538-7836.2007.02656.x

[17] Van Werkum, J.W., van der Stelt, C.A., Seesing, T.H., Hackeng, C.M. and ten Berg, J.M. (2006) A Head-to-Head Comparison between the VerifyNow P2Y12 Assay and Light Transmittance Aggregometry for Monitoring the Individual Platelet Response to Clopidogrel in Patients Undergoing Elective Percutaneous Coronary Intervention. Journal of Thrombosis and Haemostasis, 4, 2516-2518. http://dx.doi.org/10.1111/j.1538-7836.2006.02187.x

[18] von Beckerath, N., Pogatsa-Murray, G., Wieczorek, A., Sibbing, D., Schomig, A. and Kastrati, A. (2006) Correlation of a New Point-of-Care Test with Conventional Optical Aggregometry for the Assessment of Clopidogrel Responsive- 
ness. Thrombosis and Haemostasis, 95, 910-911.

[19] Price, M.F., Endermann, S., Gallopudi, R.R., Valencia, R., Stinis, C.T., Levisay, J.P., Ernst, A., Sawhney, N.S., Schatz, R.A. and Teirstein, P.S. (2008) Prognostic Significance of Post-Clopidogrel Platelet Reactivity Assessed by a Point-ofCare Assay on Thrombotic Events after Drug-Eluting Stent Implantation. European Heart Journal, 29, 992-1000. http://dx.doi.org/10.1093/eurheartj/ehn046

[20] Patti, G., Nusca, A., Mangiacapra, F., Gatto, L., D’Ambrosio, A. and Di Sciascio, G. (2008) Point-of-Care Measurement of Clopidogrel Responsiveness Predicts Clinical Outcome in Patients Undergoing Percutaneous Coronary Intervention Results of the ARMYDA-PRO (Antiplatelet Therapy for Reduction of MYocardial Damage during Angioplasty-Platelet Reactivity Predicts Outcome) Study. Journal of the American College of Cardiology, 52, 1128-1133. http://dx.doi.org/10.1016/j.jacc.2008.06.038

[21] Marcucci, R., Gori, A.M., Paniccia, R., Giusti, B., Valente, S., Giglioli, C., Buonamici, P., Antoniucci, D., Abbate, R. and Gensini, G.F. (2009) Cardiovascular Death and Nonfatal Myocardial Infarction in Acute Coronary Syndrome Patients Receiving Coronary Stenting Are Predicated by Residual Platelet Reactivity to ADP Detected by a Point-of-Care Assay. Circulation, 119, 237-242. http://dx.doi.org/10.1161/CIRCULATIONAHA.108.812636

[22] Breet, N.J., van Werkum, J.W., Bouman, H.J., Kelder, J.C., Ruven, H.J., Bal, E.T., Deneer, V.H., Harmsze, A.M., van der Heyden, J.A., Rensing, B.J., Suttorp, M.J., Hackeng, C.M. and ten Berg, J.M. (2010) Comparison of Platelet Function Tests in Predicting Clinical Outcome in Patients Undergoing Coronary Stent Implantation. JAMA, 303, 754-762. http://dx.doi.org/10.1001/jama.2010.181

[23] Price, M.J., Berger, P.B., Teirstein, P.S., Tanguay, J.F., Angiolillo, D.J., Spriggs, D., Puri, S., Robbins, M., Garratt, K.R., Bertrand, O.F., Stillabower, M.E., Aragon, J.R., Kandzari, D.E., Stinis, C.T., Lee, M.S., Manoukian, S.V., Cannon, C.P., Schork, M.J. and Topol, E.J. (2011) Sandard- vs High-Dose Clopidogrel Based on Platelet Function Testing after Percutaneous Coronary Intervention: The GRAVITAS Randomized Trial. JAMA, 305, 1097-1105. http://dx.doi.org/10.1001/jama.2011.290

[24] Kahn, S.R., Lim, W., Dunn, A.S., Cushman, M., Dentali, F., Akl, E.A., Cook, D.J., Balekian, A.A., Klein, R.C., Le, H., Schulman, S. and Murad, M.H. (2012) Prevention of VTE in Nonsurgical Patients: Antithrombotic Therapy and Prevention of Thrombosis, 9th ed: American College of Chest Physicians Evidence-Based Clinical Practice Guidelines. Chest, 141, e195S-e226S. 
Scientific Research Publishing (SCIRP) is one of the largest Open Access journal publishers. It is currently publishing more than 200 open access, online, peer-reviewed journals covering a wide range of academic disciplines. SCIRP serves the worldwide academic communities and contributes to the progress and application of science with its publication.

Other selected journals from SCIRP are listed as below. Submit your manuscript to us via either submit@scirp.org or Online Submission Portal.
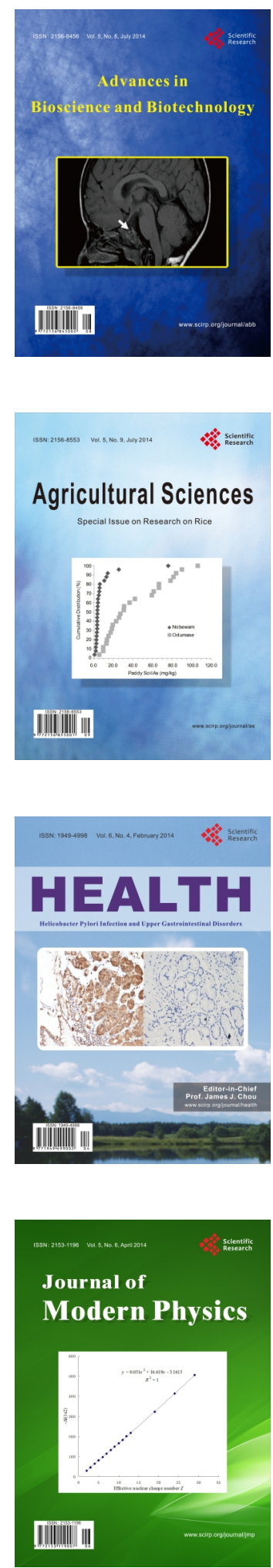
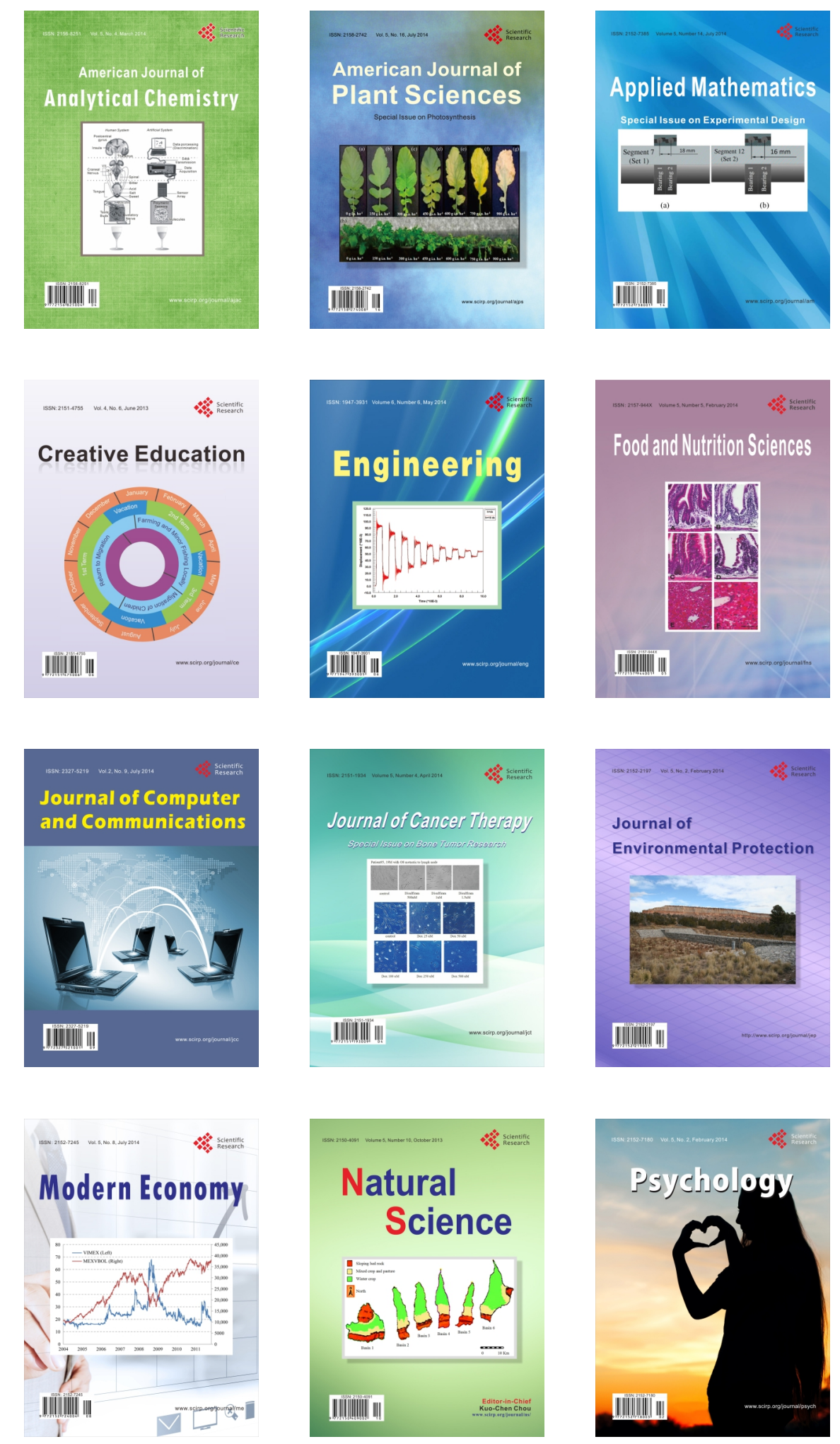